\title{
The Importance of Multidisciplinary Management during Prenatal Care for Cleft Lip and Palate
}

\author{
Hyun Ho Han ${ }^{1}$, Eun Jeong Choi ${ }^{1}$, Ji Min Kim ${ }^{1}$, Jong Chul Shin', Jong Won Rhie ${ }^{1}$ \\ Departments of ${ }^{1}$ Plastic and Reconstructive Surgery and ${ }^{2}$ Obstetrics and Gynecology, College of Medicine, The Catholic University of Korea, \\ Seoul, Korea
}

Background The prenatal ultrasound detection of cleft lip with or without cleft palate (CL/P) and its continuous management in the prenatal, perinatal, and postnatal periods using a multidisciplinary team approach can be beneficial for parents and their infants. In this report, we share our experiences with the prenatal detection of $\mathrm{CL} / \mathrm{P}$ and the multidisciplinary management of this malformation in our institution's Congenital Disease Center.

Methods The multidisciplinary team of the Congenital Disease Center for mothers of children with CL/P is composed of obstetricians, plastic and reconstructive surgeons, pediatricians, and psychiatrists. A total of 11 fetuses were diagnosed with CL/P from March 2009 to December 2013, and their mothers were referred to the Congenital Disease Center of our hospital. When $\mathrm{CL} / \mathrm{P}$ is suspected in the prenatal ultrasound screening examination, the pregnant woman is referred to our center for further evaluation.

Results The abortion rate was $28 \%(3 / 11)$. The concordance rate of the sonographic and final diagnoses was 100\%. Ten women (91\%) reported that they were satisfied with the multidisciplinary management in our center.

Conclusions Although a child with a birth defect is unlikely to be received well, the women whose fetuses were diagnosed with $\mathrm{CL} / \mathrm{P}$ on prenatal ultrasound screening and who underwent multidisciplinary team management were more likely to decide to continue their pregnancy.

Keywords Cleft lip / Cleft palate / Craniofacial abnormalities / Ultrasonography / Interdisciplinary communication
Correspondence: Jong Won Rhie Department of Plastic and Reconstructive Surgery, College of Medicine, The Catholic University of Korea, 222 Banpo-daero, Seocho-gu, Seoul 06591, Korea

Tel: +82-2-2258-6142

Fax: +82-2-594-7230

E-mail: rhie@catholic.ac.kr

Received: 11 Sep 2015 • Revised: 22 Dec $2015 \bullet$ Accepted: 28 Dec 2015

pISSN: 2234-6163 • elSSN: 2234-6171 • http://dx.doi.org/10.5999/aps.2016.43.2.153・ Arch Plast Surg 2016;43:153-159

No potential conflict of interest relevant to this article was reported.

\section{INTRODUCTION}

Cleft lip with or without cleft palate $(\mathrm{CL} / \mathrm{P})$ is one of the most common congenital facial malformations and has an incidence of one to two cases per 1,000 live births [1-4]. It is especially common in Northeast and Central Asia, and two babies per 1,000 live births (males, 1.95; females, 2.20) are affected by this malformation in South Korea [5].

Since Christ and Meininger [6] first detected CL/P using pre- natal ultrasound in 1981, prenatal ultrasonographic examinations have been performed routinely in Korea at the gestational age of 16 to 24 weeks. The accuracy of these examinations has increased as ultrasonographic technology and screening techniques have improved $[7,8]$. According to published reports, the sensitivity of this approach is $71 \%-95 \%[2,3,7-9]$.

Strong negative attitudes exist throughout the world towards children with birth defects, especially towards those with physical deformities. In South Korea, the rate of artificial termination 
of pregnancy for reasons including maternal morbidity, sexual assault, incest, or fetal abnormalities was reported to be $19.6 \%$ in 2005, which was higher than in the corresponding rate in other developed countries [10]. In Korea, abortion is permitted only in cases of maternal morbidity, sexual assault, incest, or fetal abnormalities. Therefore, the $19.6 \%$ rate of artificial termination of pregnancy only reflected legal cases of abortion, and a much higher actual rate would be expected if all cases of abortion were taken into account.

Nusbaum et al. [11] found that the prenatal detection of CL/ $\mathrm{P}$ did not increase the rate of pregnancy termination. Such detection could be of tremendous assistance in preparing the parents for the physical and psychological aspects of care for a child with $\mathrm{CL} / \mathrm{P}$ in a timely manner.

We hypothesized that women would be likely to terminate pregnancies diagnosed with fetal CL/P. In this study, we evaluated the accuracy of the prenatal ultrasound screening for $\mathrm{CL} / \mathrm{P}$, investigated the types of assistance and care that can be provided by a multidisciplinary team composed of plastic and reconstructive surgeons, obstetricians, pediatricians, and psychiatrists in our Congenital Disease Center, and assessed the effects of this care on parental decision-making.

\section{METHODS}

Our institutional review board approved the study. A total of 11 pregnant women were included in this retrospective chart review study. The fetuses were diagnosed with $\mathrm{CL} / \mathrm{P}$ and the mothers were referred to the Congenital Disease Center in our hospital from March 2009 to December 2013.

\section{Multidisciplinary approach}

The multidisciplinary team of the Congenital Disease Center for mothers of children with $\mathrm{CL} / \mathrm{P}$ is composed of obstetricians, plastic and reconstructive surgeons, pediatricians, and psychiatrists (Fig. 1). When $\mathrm{CL} / \mathrm{P}$ is suspected during the prenatal ultrasound screening examination, the pregnant woman is referred to our center for further evaluation.

Amniocentesis is performed to detect possible associated anomalies and chromosomal abnormalities in the Department of Obstetrics. The Department of Plastic and Reconstructive Surgery can provide information about surgical plans and procedures, including photographs of other children with $\mathrm{CL} / \mathrm{P}$. In the Department of Pediatrics, the parents can prepare for anticipated feeding problems and hearing difficulties. The psychiatrists provide psychological support for dealing with the feelings of guilt

\section{Fig. 1. Flow diagram of the multidisciplinary management}

Flow diagram of the multidisciplinary management of cleft lip with or without palate diagnosed during routine prenatal ultrasonographic examinations at the gestational age of 16-24 weeks in our institution.

Prenatal routine ultrasonography (16-24 wk)

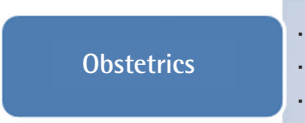

Specialized ultrasonography

- Amniocentesis

Evaluation of other associated anomaly

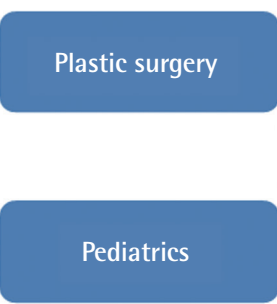

Explanation of plans of surgery

- Preoperative \& postoperative photographs

Consultation of morphological problem lip/palate
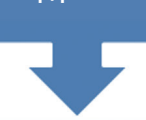

- Feeding difficulties

- Speech problems

Other complications

Emotional support 
and frustration experienced by the parents. The parents may also be enrolled in the parents-to-parents connection program for mutual support.

\section{Prenatal ultrasonography accuracy}

$\mathrm{CL} / \mathrm{P}$ cases were classified into CL (cleft lip only) and CL+P (cleft lip accompanied with cleft palate) and categorized as unilateral or bilateral during the prenatal ultrasound screening. The diagnosis was confirmed after birth by the plastic surgeons and pediatricians via physical examination, and the rate of concordance between the ultrasound screening and the ultimate diagnosis was investigated.

\section{Satisfaction with the multidisciplinary management after the prenatal diagnosis of $\mathrm{CL} / \mathrm{P}$}

The satisfaction of the parents with the multidisciplinary care received in the Congenital Disease Center was rated using the following five-item scale: very satisfied, satisfied, somewhat satisfied, somewhat unhelpful, and unhelpful.

\section{RESULTS}

The demographic data of the patients are shown in Table 1. The average age of the mothers was 30.7 years. The diagnosis of CL/ $\mathrm{P}$ was usually made at gestational week $21^{+3}$. With the exception of one woman who had hyperthyroidism and placenta previa, the mothers had no health problems that could have critically affected their babies. There were six cases of unilateral CL, four of unilateral $\mathrm{CL}+\mathrm{P}$, one of bilateral $\mathrm{CL}+\mathrm{P}$, and no cases of bilateral CL. One fetus was diagnosed with $21 \mathrm{q}$ deletion syndrome and another had associated total anomalous pulmonary venous return. Eight babies were born otherwise healthy, and three out of the 11 mothers decided to terminate their pregnancies. Thus, the abortion rate was $28 \%(3 / 11$; cases 3,5 , and 10$)$. Case 10 was aborted due to severe bilateral cleft lip and palate with chromosomal anomalies and the maternal morbidity of placenta previa. In cases 3 and 5, the parents decided to abort because of $\mathrm{CL} / \mathrm{P}$ with no other comorbidity.

The concordance rate of the sonographic and final diagnoses

\section{Table 1. Patient data}

\begin{tabular}{|ccclcc|}
\hline Case & $\begin{array}{c}\text { Maternal age } \\
(\mathbf{y r})\end{array}$ & $\begin{array}{c}\text { Gestational age } \\
(\mathbf{w k})\end{array}$ & \multicolumn{1}{c|}{ Type of cleft } & Other anomalies & Maternal morbidity \\
\hline 1 & 37 & $25^{+2}$ & Unilateral cleft lip & - & - \\
2 & 36 & $20^{+5}$ & Unilateral cleft lip & - & - \\
3 & 31 & $17^{+5}$ & Unilateral cleft lip and palate & - & - \\
4 & 26 & $24^{+2}$ & Unilateral cleft lip & - & - \\
5 & 26 & $16^{+4}$ & Unilateral cleft lip & - & - \\
6 & 31 & $20^{+5}$ & Unilateral cleft lip & - & - \\
7 & 25 & $24^{+6}$ & Unilateral cleft lip and palate & - & - \\
8 & 30 & $20^{+4}$ & Unilateral cleft lip and palate & - & - \\
9 & 33 & $23^{+3}$ & Unilateral cleft lip and palate & TAPVR & - \\
10 & 35 & $23^{+3}$ & Bilateral cleft lip and palate & 21 deletion syndrome & Hyperthyroidism, placenta previa \\
11 & 28 & $19^{+0}$ & Unilateral cleft lip & - & - \\
\hline TAPVR, total anomalous pulmonary venous return. & & & - \\
\hline
\end{tabular}

\section{Table 2. Accuracy of prenatal sonography}

\begin{tabular}{|lcccccc|}
\hline Study & $\begin{array}{c}\text { CL/P without } \\
\text { abortion }\end{array}$ & \multicolumn{2}{c}{ Anatomical diagnosis } & Sonographic diagnosis & $\begin{array}{c}\text { Correct } \\
\text { diagnosis }\end{array}$ & $\begin{array}{c}\text { False positive False negative } \\
\text { rate (\%) }\end{array}$ \\
rate (\%)
\end{tabular}


was $100 \%$ (8/8) (Table 2). Ten women reported that they were satisfied with the multidisciplinary management in our center (91\%; very satisfied in nine cases, satisfied in one case, and no response in one case) (Table 3 ).

\section{Case 1 (No. 2)}

Assessment of the fetal face during prenatal ultrasonography revealed cleft lip at $20^{+5}$ weeks. The parents were referred to the Congenital Disease Center, where they consulted with a plastic surgeon and an obstetrician. At birth, the infant had a unilateral complete cleft to the right of the philtrum with alveolar involvement. A nasoalveolar molding device with Grayson's method was inserted at the age of three weeks with alveolar approximation, and the nasal cartilage was not overstretched. The molding device was applied presurgically for approximately two months. After molding, rotation advancement cheiloplasty (Millard I method) was performed at the age of three months (Fig. 2).

\section{Case 2(No. 6)}

Left-sided cleft lip of the fetal face was detected on the prenatal

\section{Table 3. Patient satisfaction}

\begin{tabular}{|lc|}
\hline Answer & $\mathbf{n}(\%)$ \\
\hline Very satisfied & $9(81.8)$ \\
Satisfied & $1(9.1)$ \\
Somewhat satisfied & 0 \\
Somewhat unhelpful & 0 \\
Unhelpful & 0 \\
\hline
\end{tabular}

ultrasonogram at $20^{+5}$ weeks. The mother was referred to the Congenital Disease Center, where she consulted with the cleft team. She showed a strongly negative attitude towards the fetal

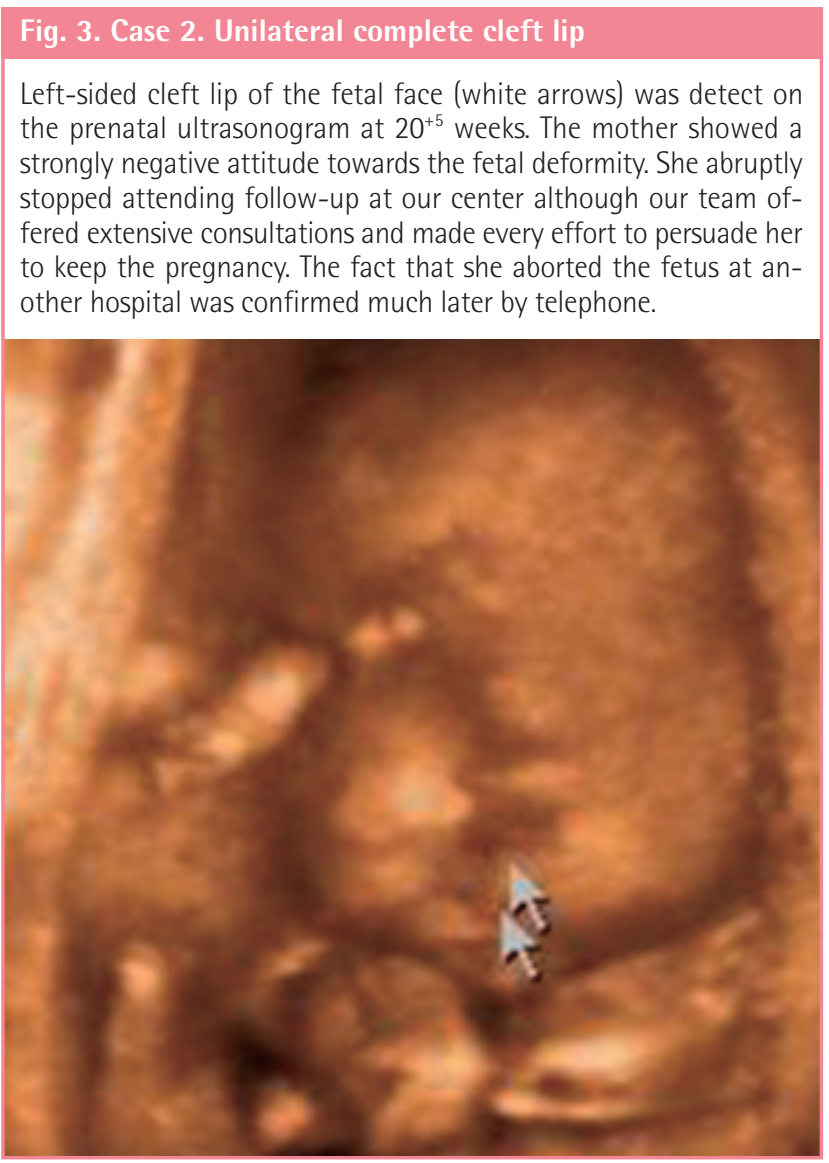

\section{Fig. 2. Case 1. Unilateral complete cleft lip}

(A) Cleft lip of the fetal face (arrow) was seen on the prenatal ultrasonogram at $20^{+5}$ weeks. (B) Three-dimensional reconstruction. (C) At birth, the infant had unilateral complete cleft lip to the right of the philtrum. A nasoalveolar molding device with Grayson's method was inserted at the age of three weeks and applied for approximately two months. (D) Cheiloplasty was performed at the age of three months.
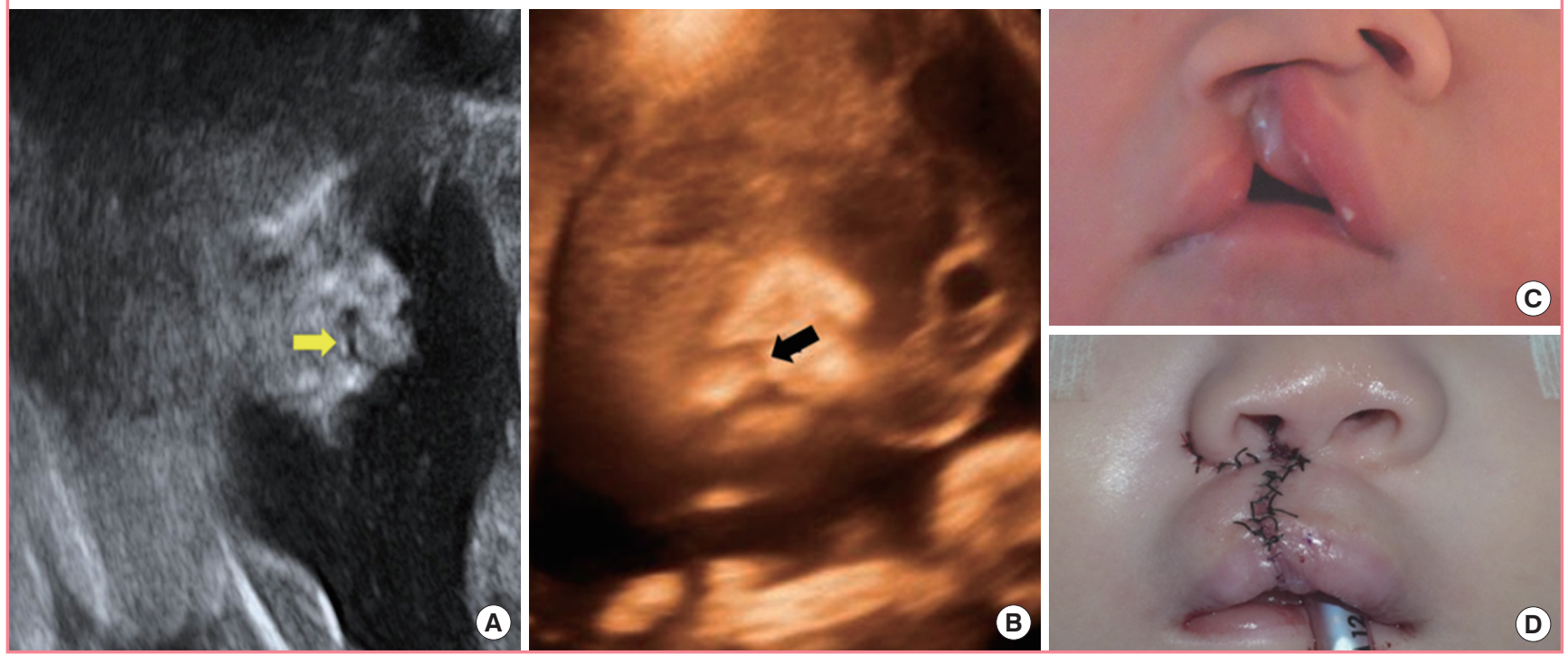
deformity and refused treatment with the goal of keeping the baby. Our team offered constant consultations with her and made every effort to persuade her to maintain the pregnancy, emphasizing the importance of life. Nevertheless, she abruptly stopped attending follow-up at our center. The fact that she aborted the fetus at another hospital was confirmed much later by telephone (Fig. 3).

\section{DISCUSSION}

The mother's fear of and feelings of repulsion towards a child with a birth defect is strong in almost every country. The rate of pro-choice opinions regarding artificial abortion if the fetus has an abnormality was found to be $54.1 \%$ in the US, $79.8 \%$ in the UK, $64.0 \%$ in Canada, and 77.4\% in Japan [10]. Practically, legal artificial abortion in cases of fetal anomalies is allowed in more than $60 \%$ of the world [10]. In Korea, a national report from 2005 indicated that approximately $35 \%$ of respondents felt that artificial abortion due to a curable fetal abnormality was acceptable, and approximately $80 \%$ felt that it was justified in cases of an incurable fetal abnormality [10]. This indicates that many Korean parents would not readily accept a fetal deformity.

According to the artificial abortion-related legislation included in the Mother and Child Health Law in Korea, legal artificial abortion is allowed before the gestational age of 24 weeks in the following cases: the gravida or her spouse has a hereditary disorder that has a high risk of affecting the fetus, the gravida or her spouse has an infectious disease that has a high risk of affecting the fetus, conception by sexual assault, conception by incest, or if maintaining the pregnancy can severely harm the gravida [10]. No clause exists to permit artificial abortion due to of fetal CL/ $\mathrm{P}$ in Korea. Artificial abortion is allowed without any restrictions of this type in the US, Canada, and most other countries in Europe. Among the Organization for Economic Cooperation and Development member countries, only Japan, Mexico, Korea, and Ireland have legal restrictions forbidding artificial abortion due to fetal abnormalities [10]. This indicates that many countries allow artificial abortion due to fetal anomalies and that feelings of repulsion towards abnormalities in offspring are strong worldwide. Thus, social and institutional care for the parent and fetus, especially if a fetal deformity is detected in a prenatal examination, is important for preventing illegal abortion in Korea. Such assistance can mitigate issues such as maternal health problems caused by illegal abortion by unlicensed practitioners.

In our Congenital Disease Center, 72\% (8/11) of the women gave birth to babies who were diagnosed with $\mathrm{CL} / \mathrm{P}$ during the prenatal ultrasound screening, and 28\% (3/11) preferred an induced abortion. The calculated abortion rate was lower than ex- pected, considering that $35 \%$ and $80 \%$ of respondents have been reported to be in favor of artificial abortion due to curable and incurable fetal abnormalities, respectively [10].

We propose that this slight decrease of the abortion rate occurred as a result of the help the parents received from the multidisciplinary management system at our center. Although the abortion rate was reported to be tenfold higher in cases with a prenatal diagnosis of $\mathrm{CL} / \mathrm{P}$ in the Netherlands, Maarse et al. [7] and Davalbhakta and Hall [13] reported that $87 \%$ and $92 \%$ of women, respectively, gave birth to their babies despite a prenatal diagnosis of $\mathrm{CL} / \mathrm{P}$ if they received prenatal counseling. Similarly to these studies, we found that a prenatal diagnosis of $\mathrm{CL} / \mathrm{P}$ did not increase the artificial abortion rate in this study.

Prenatal counseling likely needs to begin early in order for the future parents to receive adequate information about the disability, including their duties and opportunities, the types of assistance they may receive from the community, the effects the disability will have on the quality of life of their babies, and to mentally prepare themselves $[7,13]$. Plastic surgeons can explain and discuss the anticipated disabilities and treatment plans according to the child's developmental stages.

We believe that this approach may prevent parents from being influenced by incorrect information received from untrustworthy sources and strengthen the attachment between the mothers and their babies. These are likely to be the decisive factors in lowering the abortion rate. Davalbhakta and Hall [13] proposed that parents would be less psychologically traumatized by the prenatal perception of $\mathrm{CL} / \mathrm{P}$ of their babies than by its postnatal detection. Lippman [14] reported relieving parents' feelings of guilt during prenatal counseling by informing them that $\mathrm{CL} / \mathrm{P}$ has a multifactorial background and that the etiology is not yet known.

Concerns exist that the prenatal diagnosis of cleft deformity will increase the abortion rate [15-19]. Blumenfeld et al. [20] reported that $93.3 \%$ of women who tested positive for isolated fetal cleft lip in a prenatal ultrasound screening decided to terminate their pregnancy. This rate is much higher than the rate of $28 \%$ (3/11) achieved in our Congenital Disease Center [7]. Prenatal counseling by professionals and multidisciplinary team support of the parents could have been responsible for this difference.

Our study had several limitations. First, the sample number was very small, and further larger prospective randomized studies are required to generalize these results. However, even with a small sample size, the relatively high satisfaction rate shows the efficacy of multidisciplinary management. Second, although artificial abortion due to CL/P alone is illegal, the cases of abortion in our study were reported. These patients refused multi- 
disciplinary treatment for keeping the baby with a congenital deformity at our center. If they expressed such an opinion, the Department of Obstetrics offered extensive consultation and exerted considerable effort to persuade them to maintain the pregnancy. Nevertheless, it was difficult from a practical point of view to remain involved in the case management of patients who emphatically refused treatment and left our institution. It was only possible for us to confirm whether an abortion was performed a considerable amount of time later. Finally, all cases in our study had CL or CL+P, with no cases of isolated CP. The prevalence of isolated $\mathrm{CP}$ is approximately one per 2,000 births. Isolated $\mathrm{CP}$ can be identified by using specialized two- and threedimensional sonography after the gestational age of 20 weeks. The detection rate is low (about $34 \%$ and $1.4 \%$ ), especially in cases in which it was restricted to only the soft palate [21]. Therefore, the high false negative rate should be explained to the parents. If a baby is born with $\mathrm{CP}$, the baby and parent should be treated appropriately, with a similar multidisciplinary approach. In addition, a study of $\mathrm{CL} / \mathrm{P}$ showed that the official prenatal ultrasonography findings were inconsistent with the actual facial structure identified after birth [22]. Sufficient explanation and consulting is needed in these rare cases.

We wish to emphasize the benefits of a multidisciplinary team approach to the systemic management of mothers and their CL/ $\mathrm{P}$ babies. If the mother of an affected fetus is referred to a multidisciplinary team composed of obstetricians, plastic and reconstructive surgeons, pediatricians, and psychiatrists, she will undergo amniocentesis to detect the presence of associated abnormalities and will receive support and psychological counseling to relieve her feelings of guilt and to regain psychological stability. Thus, both the doctors and the future parents can prepare for the care of these babies. For these reasons, although a child with a birth defect is unlikely to be received well, the women whose fetuses were diagnosed with $\mathrm{CL} / \mathrm{P}$ on prenatal ultrasound screening and who underwent multidisciplinary team management were more likely to decide to continue their pregnancy than would have been expected.

\section{REFERENCES}

1. Abramowicz S, Cooper ME, Bardi K, et al. Demographic and prenatal factors of patients with cleft lip and cleft palate: a pilot study.J Am Dent Assoc 2003;134:1371-6.

2. Sohan K, Freer M, Mercer N, et al. Prenatal detection of facial clefts. Fetal Diagn Ther 2001;16:196-9.

3. Cash C, Set P, Coleman N. The accuracy of antenatal ultrasound in the detection of facial clefts in a low-risk screening population. Ultrasound Obstet Gynecol 2001;18:432-6.
4. Moss A. Controversies in cleft lip and palate management. Ultrasound Obstet Gynecol 2001;18:420-1.

5. Ministry of Health and Welfare. The necessity for reinforcement of guarantee of insurance for the surgery of cleft lip and palate [gusungugaeyeol susul bojangseongganghwa pilyo] [Internet]. Sejong: Ministry of Health and Welfare. 2013 [cited 2016 Feb 1]. Available from: http://stat.mw.go. $\mathrm{kr} /$ front/notice/statPressReleaseView.jsp?menuId $=31 \& \mathrm{bb}$ $\mathrm{sSeq}=4 \& \mathrm{nttSeq}=20541 \& \mathrm{nPage}=1 \&$ searchKey $=\&$ searchW ord $=\&$ sttsDataSeq $=$.

6. Christ JE, Meininger MG. Ultrasound diagnosis of cleft lip and cleft palate before birth. Plast Reconstr Surg 1981;68: 854-9.

7. Maarse W, Pistorius LR, Van Eeten WK, et al. Prenatal ultrasound screening for orofacial clefts. Ultrasound Obstet Gynecol 2011;38:434-9.

8. Rotten D, Levaillant JM. Two- and three-dimensional sonographic assessment of the fetal face. 2 . Analysis of cleft lip, alveolus and palate. Ultrasound Obstet Gynecol 2004;24:40211.

9. Nyberg DA, Sickler GK, Hegge FN, et al. Fetal cleft lip with and without cleft palate: US classification and correlation with outcome. Radiology 1995; 195:677-84.

10. Ministry of Health and Welfare. The research on the actual condition of artificial abortion and establishment of comprehensive countermeasures [ingongimsinjungjeol siltaejosa mich jonghabdaechaegsulib], 2005 [Internet]. Sejong: Ministry of Health and Welfare. 2008 [cited 2016 Feb 1]. Available from: http://stat.mw.go.kr/front/statData/publicationView.jsp?menuId $=47 \&$ bbsSeq $=13 \&$ nttSeq $=10104 \&$ searchKey $=\&$ searchWord $=\&$ nPage $=7$.

11. Nusbaum R, Grubs RE, Losee JE, et al. A qualitative description of receiving a diagnosis of clefting in the prenatal or postnatal period.J Genet Couns 2008;17:336-50.

12. Maarse W, Berge SJ, Pistorius L, et al. Diagnostic accuracy of transabdominal ultrasound in detecting prenatal cleft lip and palate: a systematic review. Ultrasound Obstet Gynecol 2010; 35:495-502.

13. Davalbhakta A, Hall PN. The impact of antenatal diagnosis on the effectiveness and timing of counselling for cleft lip and palate. Br J Plast Surg 2000;53:298-301.

14. Lippman A. Embodied Knowledge and Making Sense of Prenatal Diagnosis. J Genet Couns 1999;8:255-74.

15. Hulnick SJ. Ultrasound diagnosis of clefts. Plast Reconstr Surg 1982;70:118-9.

16. Hallock G. In defense of ultrasound diagnosis of cleft lips in utero. Plast Reconstr Surg 1983;71:443.

17. Matthews MS, Cohen M, Viglione M, et al. Prenatal coun- 
seling for cleft lip and palate. Plast Reconstr Surg 1998;101: 1-5.

18. Duboys EB. Prenatal counseling for cleft lip and palate. Plast Reconstr Surg 1998;102:278.

19. Bronshtein M, Blumenfeld I, Blumenfeld Z. Early prenatal diagnosis of cleft lip and its potential impact on the number of babies with cleft lip. Br J Oral Maxillofac Surg 1996;34: 486-7.

20. Blumenfeld Z, Blumenfeld I, Bronshtein M. The early pre- natal diagnosis of cleft lip and the decision-making process. Cleft Palate Craniofac J 1999;36:105-7.

21. Wilhelm L, Borgers $\mathrm{H}$. The 'equals sign': a novel marker in the diagnosis of fetal isolated cleft palate. Ultrasound Obstet Gynecol 2010;36:439-44.

22. Kim DW, Chung SW, Jung HD, et al. Prenatal ultrasonographic diagnosis of cleft lip with or without cleft palate; pitfalls and considerations. Maxillofac Plast Reconstr Surg 2015;37: 24. 